\title{
ARISTÓTELES Y CARL SCHMITT SOBRE EL DERECHO NATURAL
}

\author{
Hugo Eduardo Herrera* \\ hugo.herrera@udp.cl
}

RESUMO De acordo com as interpretações mais conhecidas (por exemplo, Hofmann, Strauss, Löwith ou Kuhn), o pensamento jurídico e político de Carl Schmitt mantém distância de Aristóteles. Este artigo tem a intenção de mostrar que a concepção de direito de Schmitt, apesar de ser desenvolvida em um contexto diferente, contém semelhanças significativas com o entendimento de direito em Aristóteles. Para mostrar essa proximidade, considera-se especialmente a noção de totalidade presente no conceito aristotélico de polis, que implica que a unidade política é o principal modo de se realizar o direito.

Palavras-chave Aristóteles, Carl Schmitt, Direito como ordem, Totalidade da polis, Estado de exceção.

ABSTRACT According to mostly known interpretations (e.g.: Hofman, Strauss, Löwith or Kuhn), the legal and political thought of Carl Schmitt keeps distance from Aristotle's. This article intends to show that Schmitt's concept of law, despite developed in a different context, holds significant likelihood with Aristotle's comprehension of law. With the Purpose of building this proximity, the notion of entirety present in the Aristotelic concept of polis implies that political unit is the main way to accomplish law.

Keywords Aristotle, Carl Schmitt, Law as order, Entirety of the polis, State of exception.

* Profesor del Instituto de Humanidades de la Universidad Diego Portales, Chile. Artigo recebido em 07/01/2013 e aprovado em 13/03/2013. 


\section{Distancia y cercanía entre Aristóteles y Schmitt}

Nombrar juntos a Aristóteles y Carl Schmitt puede llamar la atención en varios sentidos. De un lado, se trata de autores que operaron en contextos radicalmente distintos: Aristóteles es el fundador de la política como disciplina y escribe en la época de la decadencia de la polis. Schmitt, en cambio, es un jurista y teórico político que desarrolla su obra en medio de la crisis del Estado y del Derecho internacional público interestatal. Pero, además, la mayor parte de la literatura sobre Carl Schmitt ha caracterizado la obra de este autor de tal manera que ella queda, precisamente, separada de la filosofía política de Aristóteles. ${ }^{1}$ Basta acudir a la definición schmittiana de lo político según los criterios de amigo y enemigo, o al existencialismo de Schmitt, expresado en sus teorías del conflicto, del estado de excepción o de la dictadura, para obtener ejemplos de lo que -a menos que se hagan importantes aclaraciones-no es la filosofía política del Estagirita.

En sucesivos trabajos, he intentado tanto mostrar la posición que Carl Schmitt ocupa respecto de la filosofía práctica de raigambre aristotélica en general, ${ }^{2}$ cuanto hacer un contrapunto entre el "Concepto de lo político" de Schmitt y la comprensión política que se expresa en el libro I de la "Política", especialmente en sus dos primeros capítulos. Con ocasión de esas investigaciones previas, pude descubrir una similitud entre ambos autores, que me interesa desarrollar aquí, a saber, el parecido entre la concepción aristotélica de lo justo natural y las ideas schmittianas de unos principios jurídicos previos al derecho positivo y del Estado como realización del derecho. Si para Aristóteles la polis es el modo privilegiado de realizar la justicia, algo similar ocurre en Schmitt: el Estado es el modo privilegiado de realizar el derecho, un derecho que no se agota en su mera positividad, sino que se amplía hacia ciertos contenidos de justicia.

La tesis según la cuál existe una cierta cercanía entre el pensamiento jurídico schmittiano y la teoría tradicional del derecho natural, ha sido afirmada, de una manera u otra, por diversos autores como Hans Welzel, ${ }^{3}$ Joseph Kaiser, ${ }^{4}$

4 "Naturalmente a él le eran familiares la concepción católica de la sociedad y el Estado, para la cual el orden es uno de sus conceptos fundamentales y Dios, que determina su creación como cosmos, aparece como origen de todo orden" (Kaiser, 1988, p. 329). 
Ernst-Wolfgang Böckenförde, ${ }^{5}$ Ernst Rudolf Huber, ${ }^{6}$ Montserrat Herrero, ${ }^{7}$ Henning Ottmann ${ }^{8}$ y Gerhardt Niemeyer. ${ }^{9}$ Especialmentente a partir de los años treinta, con la teoría schmittiana del orden jurídico concreto, Schmitt se autocomprende como cercano a aquella tradición y vincula su pensamiento jurídico del orden con Tomás de Aquino y Aristóteles. ${ }^{10}$ Esta vinculación está empero implícita ya en obras previas, como, por ejemplo, "El valor del Estado y la importancia del individuo". ${ }^{11}$ Aquí pretendo acotar la tesis específicamente a la relación de Schmitt con Aristóteles, dejando de lado la evolución posterior de la llamada teoría del derecho natural, desde el Estagirita hasta Tomás. ${ }^{12}$

La novedad de este trabajo radica en que en él se aborda la vinculación de Aristóteles con Schmitt en el tema preciso del derecho natural, la cual no ha sido hasta ahora suficientemente tratada, sino, en lo fundamental, simplemente señalada. Por el contrario, existen aspectos llamativos del pensamiento schmittiano, que han dado pié, como he mencionado, a destacados intérpretes para distanciarle del Estagirita. Para esclarecer esta vinculación, me detendré a considerar diversos sentidos de totalidad, según los cuales Aristóteles comprende la polis, todos los cuales son, en mayor o menor medida, compartidos por Schmitt. Además del interés que el estudio de esa relación, al modo en el cual lo propongo, tiene para la determinación de la posición del pensamiento jurídico schmittiano, pienso que la indagación en ese pensamiento jurídico puede servir -y es lo que intento hacer en el último punto- para determinar su validez y alcances sistemáticos.

En lo que sigue, me referiré, primeramente (II), a tres aspectos del pensamiento de Schmitt que parecen implicar su necesaria distancia con el Estagirita: la concepción del Estado como Estado de derecho, las afirmaciones críticas de Schmitt respecto de la doctrina del derecho natural, en fin, la importancia que adquiere la excepción en su obra. Luego (III) abordaré el pensamiento político de Aristóteles interpretándolo, como he indicado, a partir del concepto de totalidad. Trataré de mostrar que la polis es, para el Estagirita, una

5 "Según la autocomprensión de Schmitt, el orden concreto tiene un precedente en el derecho natural medieval aristotélico-tomista" (Böckenförde, 1984, col. 1314).

6 Cf. Huber, 1941, p. 8.

7 A pesar de las particularidades de su pensamiento, Herrero Schmitt se deja ubicar en lo que llama la "tradición aristotélico-tomista" (Herrero, 1997, p. 171, nota al pié); cf. pp. 155-196.

8 Henning Ottmann entiende que Schmitt intenta una "renovación del pensamiento del orden", y le compara con Leo Strauss y Eric Voegelin; Ottmann, 1995, columna 191.

9 Cf. Niemeyer, 1934, p. IX (nota al pié).

10 Cf. Schmitt, 1993a, p. 41.

11 Schmitt, 2004.

12 Derecho natural significa algo muy distinto en Aristóteles, para quien es fundamentalmente orden, y en autores posteriores, que se inclinan hacia el normativismo. Sobre la oposición entre uno y otro tipo de pensamiento, cf. Böckenförde, 1984, cols. 1312-1315. 
unidad total, en al menos tres sentidos, compartidos todos por Schmitt. Estos sentidos de totalidad permiten pensar en una mayor cercanía entre ambos que la que los autores habitualmente admiten, precisamente en el tema del derecho natural. Una última parte (IV) la dedicaré a plantear el problema que representa para el pensamiento schmittiano, y para todo pensamiento jusnaturalista, el concepto de excepción. En la medida en que ese concepto es explícitamente considerado por Schmitt como base de su teoría política, aquél problema adquiere en ella un carácter especialmente intenso.

\section{Tres posiciones distantes}

En "El valor del Estado y la importancia del individuo", Schmitt indica: "no hay otro Estado que el Estado de derecho". ${ }^{13}$ Esta afirmación puede significar, de un lado, el reconocimiento positivista al hecho de que cualquier Estado, en tanto que institución, sólo puede actuar por medio de normas y decisiones jurídicas, cualquiera que sea el contenido de esas normas. Como el Estado actúa de ese modo, no se le puede negar al Estado su carácter de Estado de derecho simplemente porque el contenido de sus normas no coincide con una determinada concepción de la justicia. En esta lectura del texto, Schmitt se acerca por ejemplo, a Hans Kelsen, para quien efectivamente el Estado no puede sino ser jurídico. Sostener la posibilidad de una diferencia entre Estado y derecho no obedece a un razón científico jurídica, sino a un motivo ideológico: legitimar al Estado en tanto que organización de la violencia, por medio del derecho. ${ }^{14}$ La afirmación de Schmitt también puede significar, sin embargo, una especie de enaltecimiento del Estado de corte idealista, al estilo de Hegel, como la "realidad efectiva de la idea ética". ${ }^{15}$ No es, entonces, que todo Estado sea Estado de derecho porque el derecho positivo es el modo de actuar del Estado, sino que todo Estado es de derecho pues el Estado encarna un ideal, la juridicidad misma. La racionalidad jurídica se realiza mediante la acción del Estado y el Estado es entonces el realizador de contenidos jurídicos ideales.

Más allá de las distintas implicancias que tienen ambas lecturas, en los dos casos, empero, puede espetarse que la crítica del Estado queda clausurada, pues en ambos casos Estado y derecho se encuentran esencialmente relacionados, de tal suerte que, en definitiva, y si se hace caso sólo a esta frase, jamás puede 
el Estado actuar sino jurídicamente. Nunca se podrá criticar al Estado concreto por salirse del derecho, por violarlo, por volverse una instancia puramente fáctica, mero poder. La positivación radical del Estado y su idealización coinciden en esta carencia, en la falta de criterios mediante los cuales pueda juzgarse si acaso el Estado es o no de derecho. Hasso Hofmann ha mostrado, en un sentido similar, la distancia que, a su juicio, guarda Schmitt con la doctrina tradicional del derecho natural. En El valor del Estado, el "enunciado jurídico estatal" es, para Schmitt, a su juicio, "la única forma de aparición del derecho en absoluto". ${ }^{16} \mathrm{Y}$ esto significa la negación de "todo criterio de contenido" a partir del cual se pueda determinar el grado de realización del derecho. ${ }^{17}$

En Aristóteles, en cambio, la política queda atada a consideraciones morales. Para Aristóteles la política es siempre una forma de praxis, determinada por principios de contenido que rigen la praxis en cuanto tal. Ya en las primeras frases de la "Política", indica Aristóteles la vinculación entre la polis como la forma de organización política y su concepción del bien como principio rector de todas las acciones. ${ }^{18}$ En el caso de la polis como organización más perfecta, este bien será también el más perfecto. ${ }^{19}$ También en el capítulo 2 del libro I señala que la "vida más perfecta" 20 es el fin o bien perseguido y logrado por la polis, y que el carácter político del ser humano se evidencia porque éste tiene un "sentido" no sólo para lo placentero o doloroso, sino también para "bueno y malo", ${ }^{21}$ sentido que sólo podría realizarse con plenitud en la polis. Son múltiples las referencias al carácter moral de la política. Si bien es cierto que en la obra del Estagirita existe una relativa independencia de ambos ámbitos, ${ }^{22}$ no es posible, empero, llegar a pensar en una separación, de tal suerte que se pueda afirmar una acción propiamente política y jurídica legítimamente independiente de principios morales de contenido, como sí sería posible que ocurra si se hace caso a la obra de Schmitt.

Existe una serie de textos en los cuales Schmitt toma distancia explícitamente del jusnaturalismo. Schmitt tiene plena lucidez de las limitaciones de la teoría del derecho natural en un contexto radicalmente diverso a aquél en el cual emergió. A diferencia de la época de Aristóteles o

16 Hofmann, 2002, p. 52.

17 Schmitt, 2004, p. 57.

18 Cf. Aristóteles, "Política" I, 1, 1252a 1-7 (uso la edición del Centro de Estudios Constitucionales, Madrid, 1989a); "Ética a Nicómaco" I, 1, 1094a 1-b 12 (uso la edición del Centro de Estudios Constitucionales. Madrid, 1989b).

19 Aristóteles, "Política" I, 1, 1252 a 1-7.

20 Aristóteles, "Política" I, 2, 1252 b 28.

21 Aristóteles, "Política" I, 2, 1253a 15-16.

22 Cf. las distinciones de Günther Bien entre ética y política en Aristóteles (Bien, 1981, pp. XVII-LIII). 
Tomás de Aquino, donde naturaleza significa aún una estructura teleológica, luego de la aparición de la ciencia natural moderna, ese concepto entra en crisis. La naturaleza se escinde del sentido. ${ }^{23}$ Precisamente por eso, porque escribe dentro de un contexto determinado por la revolución científica, es que cuando habla de "derecho natural" en "El valor del Estado" limita la expresión, agregándole: "sin naturalismo". ${ }^{24}$ Schmitt es consciente de que el empleo no-teleológico de la expresión importa el riesgo de caer en el error lógico sobre el cual David Hume llamó la atención: a partir de enunciados sobre hechos, comprendidos como conjunto de datos sensoperceptibles, es lógicamente imposible inferir enunciados normativos. ${ }^{25} \mathrm{O}$, como el mismo Schmitt señala: "A partir de la descripción de la naturaleza, a la cual también corresponde la vida en común de los seres humanos, en tanto que meramente es un asunto de la ciencia social que constata y explica, no puede emerger derecho alguno". ${ }^{26}$ Un concepto naturalista de derecho natural "daría lugar hoy en día, en el mejor de los casos, a un derecho biológico". ${ }^{27}$ Por eso puede Schmitt escribir también, consecuentemente: "Derecho natural es una palabra conducente a error y anacrónica en la época de las ciencias naturales y del dominio de sus resultados concretos". 28

Para Álvaro d'Ors, tras el rechazo al empleo de la expresión "derecho natural" por parte de Schmitt, se halla la aceptación del nuevo concepto científico-natural de naturaleza. ${ }^{29}$ Según esta indicación, Schmitt no sólo se distancia de la expresión "derecho natural", sino del contenido de la doctrina del derecho natural clásica, según la cual la naturaleza implica ya ella misma un cierto sentido o teleología. Ese sentido o teleología son inadmisibles en la nueva comprensión científico-natural, de tal suerte que si Schmitt adhiere a ésta, no puede sino distanciarse fundamentalmente del concepto jusnaturalista de naturaleza como teleología, que es el concepto con el cual opera Aristóteles.

Para el Estagirita, la "naturaleza" es "fin". ${ }^{30}$ En el caso de la naturaleza del ser humano, ese fin es la polis. De esta observación puede luego Aristóteles decir que al ser humano le corresponde la polis como lugar de su plenitud, "por naturaleza". ${ }^{11}$ Este concepto permite salvar el error lógico detectado por

23 Cf. Herrera, 2010b, pp. 49-66.

24 Schmitt, 2004, p. 77.

25 Cf. Hume, 1960, pp. 460-461.

26 Schmitt, 2004, p. 36.

27 Schmitt, 1991a, p. 50.

28 Schmitt, 1991a, p. 195.

29 Cf. D'Ors, 1996, p. 37.

30 Aristóteles, "Política" I, 2, 1252b 31-35.

31 Aristóteles, "Política" I, 2, 1252 b 31. 
Hume, pues en él la naturaleza de algún modo ya contiene el deber. Que el ser humano sea político porque sólo en la polis alcanza su despliegue natural importa en cierta manera que el ser humano debe vivir en la polis. Este concepto se halla, empero, en crisis desde la revolución científico-natural. En la comprensión científica moderna algo así como un fin o sentido de la naturaleza es metódicamente dejado de lado, de tal suerte que la naturaleza no es ya criterio.

En “Teología política”, los criterios y reglas generales de carácter práctico parecen sucumbir ante la relevancia que le otorga Schmitt allí a la situación excepcional y la decisión soberana que establece el estado de excepción. ${ }^{32}$ En "El concepto de lo político", de su lado, amigo y enemigo, los criterios determinantes de dicho ámbito, son para Schmitt "independientes"33 respecto de normas morales o de un derecho natural. ${ }^{34} \mathrm{La}$ acción política, determinada por el conflicto, no se halla atada a regulaciones previas. En la guerra, las justificaciones morales caen y sólo tiene aquí sentido un actuar existencial. "No hay ningún fin racional, ninguna norma tan correcta, ningún programa tan ejemplar, ningún ideal social tan bello, ninguna legitimidad o legalidad que pueda justificar que seres humanos se maten unos a otros por ello". ${ }^{35}$

En estos textos, observan los intérpretes, Schmitt parece separarse de la tradición jusnaturalista fundada por Aristóteles. El soberano de "Teología política" y el individuo existencial de "El concepto de lo político" no se hallan atados a un determinado contenido, sino, antes que eso, a la decisión como tal. Vale decir, están en cierto modo decididos por la decisión. Esta actitud, empero, les impide alcanzar la esfera propiamente política y sus contenidos y hace de ellos algo así como un complemento del individuo liberal, al cual Schmitt critica. ${ }^{36}$ Tal como el liberal niega la esfera política y queda atado al mundo del espíritu y la economía, el soberano y el individuo existencial están decididos por la decisión: por declarar la excepción, por el sacrificio y la guerra, sin preguntar por los contenidos legitimadores de una decisión correcta. ${ }^{37}$

El rechazo de Schmitt a reconocer criterios morales capaces de vincular la esfera específicamente política deriva, a juicio de los intérpretes, de la relevancia que en su teoría adquiere la excepción, la situación de conflicto, la guerra, sea interna o externa. ${ }^{38} \mathrm{El}$ concepto de enemigo opera, en este contexto,

32 Cf. Schmitt, 2009, pp. 13-21.

33 Schmitt, 1997b, pp. 26-27.

34 Cf. Kuhn, 1967, pp. 447-448, 458-459; Thielicke, 1987, p. 160; Gerhardt, 2003, p. 217; Laufer, 1961, pp. 45, 50, 156-162, 165; Löwith, 1984, p. 44-49; Hofmann, 2002, pp. 94-116; Heller, 1934, p. 314.

35 Schmitt, 1997b, pp. 49-50.

36 Cf. Schmitt, 1997b, pp. 68-78.

37 Cf. Strauss, 1998, p. 123; Kuhn, 1967, pp. 458-459; Löwith, 1984, p. 103.

38 Cf. Schmitt, 2009, pp. 19-21; Schmitt, 1997b, p. 32-33, 45-54. 
como encarnación de la crisis. Su presencia me pone en crisis. En la crisis, el orden y la normalidad caen. Allí dejan de valer las normas jurídicas e, incluso, las normas morales. Es decir, no sólo son desobedecidas, no sólo pierden su eficacia, sino que pierden su sentido normativo mismo, dejan de significar como normas vinculantes. ${ }^{39} \mathrm{El}$ orden, la "situación normal" es para Schmitt la condición de la validez de las normas, incluidas las normas morales y jurídicas: "porque toda norma supone una situación normal y ninguna norma puede tener validez en una situación para ella completamente anormal" ${ }^{40} \mathrm{En}$ una guerra de todos contra todos, por ejemplo, no ocurriría simplemente que las normas que resguardan vida y propiedad pierdan su eficacia; ellas pierden simplemente su significado como normas.

Esta condición, que rige para las normas jurídicas y morales, se acentúa especialmente en el caso de estas últimas, pues ellas no alcanzan para dar cuenta de aquella situación en la que todo, incluso la propia vida, queda puesto en juego.$^{41}$ Lo político así estaría estructuralmente condenado a ser autónomo de la moral en los casos más serios, precisamente porque con el reconocimiento de la presencia del enemigo como "posibilidad real", ${ }^{42}$ Schmitt estaría dejando entrar en su construcción teórica el caos, la excepción, la situación en la cual las reglas pierden ya su validez.

Hemos visto ya que para Aristóteles la política es siempre una forma de praxis, determinada por los principios que rigen la praxis en cuanto tal y que, aunque entre ética y política hay una relativa independencia, no se puede llegar allí a afirmar una acción propiamente política legítimamente independiente de la moral, como sí sería posible que ocurra si se hace caso a la obra de Schmitt.

\section{Lo político como lo total en Aristóteles}

Hasta ahora he constatado tres diferencias relevantes entre el pensamiento de Schmitt y el pensamiento del derecho natural en Aristóteles. Si se atiende, empero, a la concepción política de Aristóteles y se repara especialmente en lo que se podría llamar la totalidad de la polis, resulta entonces que la distancia entre Schmitt y Aristóteles comienza a estrecharse. 
En Aristóteles la polis tiene un carácter total en al menos tres sentidos. Primero, porque la polis es la unidad económica y militarmente autosuficiente. La polis nace por las necesidades de la vida ${ }^{43}$ y en ellas tiene su primera justificación. Ya en este nivel, el ser humano no es autosuficiente, sino que requiere de sus semejantes. Segundo, la polis es total porque ella es condición de lo específicamente humano. Para vivir fuera de la polis hay que ser o más que un humano o menos que un humano. El humano, en cambio, vive y se constituye recién en la polis. Es ahí que se adquiere y ejercita un lenguaje complejo, capaz de comprender no sólo lo placentero o doloroso, sino también lo justo, lo bueno. ${ }^{44} \mathrm{El}$ lenguaje, como condición de lo humano, se despliega de la manera más plena en el ejercicio deliberativo y reflexivo que tiene lugar en la polis. ${ }^{45}$ En tercer lugar, la polis es total, pues ella es una unidad previa a la división entre derecho natural y derecho positivo. El derecho de la polis es - podría decirse enfatizando-el derecho natural mismo.

Aristóteles distingue lo justo natural de lo justo positivo, pero la distinción no le impide reconocer que lo justo mismo es, en el sentido más propio, el derecho realizado. Lo justo mismo es la realización del derecho en la polis. Fuera de la polis, entiende Aristóteles que no habría derecho y justicia, sino salvajismo o barbarie. Es recién con la instauración de la polis que el derecho y la justicia existen. ${ }^{46}$ En Aristóteles, además, lo justo natural y lo justo convencional son las formas de lo justo político. "Lo justo político se divide en lo natural y lo legal". ${ }^{47}$ El texto fundador de la tradición de pensamiento jusnaturalista de raigambre aristotélica y según el cual junto al derecho positivo existe un derecho natural, los pone a ambos bajo el concepto superior de lo justo político. Sin perjuicio de los problemas de esta ordenación, en un, por lo demás, muy difícil texto aristotélico, la intención del Estagirita parece ser la de mostrar que el derecho y lo justo tienen un carácter fundamentalmente político en el sentido de que sólo en la polis encuentra el derecho su realización más plena. Sólo allí donde "se halla una cantidad de hombres libres e iguales en comunidad para el fin de la plena autosuficiencia". ${ }^{48}$ Porque lo justo en su sentido más pleno es el derecho realizado, es que, en fin, ante el conflicto

43 Cf. Aristóteles, "Política" I, 2, 1253a 29.

44 Cf. Aristóteles, "Política" I, 2, 1253a 15-16.

45 Sólo deliberativamente se dejan zanjar las diferencias entre libres e iguales ("Política" I, 7, 1255b 16) y mediar el cambio de posición entre gobernantes y gobernados ("Política" I, 12, 1259b 5-6).

46 Cf. Aristóteles, "Política" I, 2, 1253a 1-8, 27-32.

47 Aristóteles, "Ética a Nicómaco" V, 10, 1134b 18.

48 Aristóteles, "Ética a Nicómaco" V, 10, 1134a 25-27. 
entre orden y ley, para Aristóteles debe prevalecer el orden y ceder la ley, la cual debe ser corregida mediante equidad. ${ }^{49}$

Los tres sentidos de totalidad son relevantes, pues los tres acercan a Aristóteles a la concepción schmittiana del derecho. En "El valor del Estado", Schmitt le atribuye a la unidad política un papel total en los mismos tres sentidos en los que lo hace el Estagirita. Para Schmitt la autosuficiencia, expresada como capacidad soberana, es signo distintivo de la unidad política. Sólo cuando la unidad política es capaz de sobreponerse a todas las otras unidades y fuerzas que pujan, tanto en su interior como desde el exterior, es que ella propiamente existe. ${ }^{50}$

Para Schmitt, nuestro destino es político. ${ }^{51}$ Fuera de la polis, no viven propiamente seres humanos, pues no hay cómo suspender la dialéctica permanente de unidad-oposición, amigo-enemigo, ya que es el ser humano la fuente misma del conflicto, la excepción (Ausnahme), el acontecimiento (Ereignis). La existencia humana es misteriosa, precaria, suspendida sobre la trascendencia y el misterio. El ser humano está, desde que emerge en el mundo, bajo amenaza..$^{52}$ Asimismo, su consciencia originaria no es meramente teórica, sino, desde siempre, práctica. La tensión y la diferencia se encuentran ya en nosotros mismos. Ella es la base antropológica de la distinción amigoenemigo. ${ }^{53}$ Es allí, en esta doble estructura precario-práctica, no en factores históricos, donde radica la fuente última de la unión y del conflicto, es decir, de la política.

La posición de Schmitt se revela, además, bastante parecida a la del Estagirita, cuando afirma que la unidad política es la forma de realización del derecho, sino la única, cuanto menos una privilegiada. Al igual que en Aristóteles, el interés fundamental de Schmitt es, precisamente, ese derecho realizado, cómo puede realizarse, cuáles son los límites de su realización. Ya en "Teología política" repara en la necesidad de un orden previo realizado para la existencia del derecho y cuestiona la posibilidad de la validez de las normas jurídicas en una situación de caos político. ${ }^{54}$ En "Teoría de la constitución", por su parte, piensa un concepto de constitución como orden ${ }^{55}$ y formula su teoría de las garantías institucionales. ${ }^{56}$ No es, empero, hasta

49 Cf. Aristóteles, "Ética a Nicómaco" V, 14, 1137a 31-1138a 4.

50 Cf. Schmitt, 1997b, pp. 39, 43.

51 Cf. Schmitt, 1997b, p. 77.

52 Cf. Schmitt, 2009, p. 21; Schmitt, 1997b, p. 60.

53 Cf. Schmitt, 2002, pp. 89-90.

54 Cf. Schmitt, 2009, p. 19.

55 Cf. Schmitt, 1993b, §1.

56 Cf. Schmitt, 1993b, § 14. 
1933-1934 que desarrolla con plena consciencia su teoría del derecho como orden y formula los argumentos que le darán sustento. También su concepto de Nomos, como orden concreto que emerge de la toma de posesión de un grupo humano de la tierra, que Schmitt elabora especialmente en los años 1950, es expresión y un desarrollo del pensamiento del orden, ${ }^{57}$ cuyo punto de arranque es el nomos aristotélico. ${ }^{58}$ Tanto la idea del Estado como realizador del derecho, y en este sentido, su calificación del Estado, cuando existe, como Estado de derecho, cuanto su afirmación del derecho como orden, concuerdan en lo fundamental con el pensamiento aristotélico.

El reconocimiento de la importancia del orden como derecho realizado, y de la unidad política como realizadora del derecho, no significan, empero, que Schmitt desconozca principios de justicia suprapositivos. Schmitt afirma principios de justicia suprapositivos, cuya existencia no es diversa de sus realizaciones institucionales. Así, si bien indica efectivamente que "no hay otro Estado que el Estado de Derecho", ${ }^{59}$ con ello no está simplemente afirmando el cinismo o la imposibilidad de un estudio crítico del Estado. Simplemente está enfatizando el papel de realizador del Derecho que le corresponde a la unidad política. Schmitt entiende que siempre es posible realizar una crítica del Estado concreto, de "cuán lejos la idea se ha vuelto realidad" ${ }^{60}$ Lo que ocurre es que para Schmitt la idea sin realización no tiene más que un sentido derivado. En verdad, no hay derecho, no hay derecho natural en el sentido más propio de la expresión, de manera similar a Aristóteles, mientras que el Estado no lo realice.

Schmitt habla en "El valor del Estado" de contenidos o "pensamientos jurídicos", ${ }^{61}$ de los cuales un ejemplo es "el enunciado, respeta a tu prójimo". ${ }^{62}$ En "Die Lage der europäischen Rechtswissenschaft", escribe sobre "el fundamento de un racional ser-humano, del cual no pueden prescindir los principios del derecho. A estos principios pertenece un reconocimiento de la persona que descansa en el reconocimiento mutuo y que no cae ni aún en la lucha; sentido para la lógica y la consecuencia de los conceptos e instituciones; sentido de reciprocidad y para el mínimo de un procedimiento ordenado, un due process of law, sin el cual no hay derecho". ${ }^{63}$ 
Con la afirmación de principios suprapositivos de justicia Schmitt se distancia del positivismo kelseniano, para el cuál dichos contenidos o pensamientos son asunto de meros deseos o temores, pero no de algún tipo de conocimiento. ${ }^{64}$ Con criterios jurídicos de contenido, Schmitt puede criticar también la concepción hegeliana de la historia y con ello también todo intento de ensalzar más de la cuenta al Estado concreto. La que Schmitt llama la comprensión histórico-filosófica de la historia carece de criterios independientes respecto al acontecer histórico, según los cuales juzgar ese mismo acontecer. ${ }^{65}$ A su juicio, la visión histórico-filosófica absolutiza el acontecer histórico, y sus momentos son tenidos simplemente como etapas en un proceso de progreso, el cual termina siendo tenido como valioso en sí mismo. ${ }^{66} \mathrm{Si}$ la historia es un proceso progresivo, donde todas las etapas y sus acontecimientos quedan justificados como momentos del proceso, entonces no resulta ya posible juzgarlas con independencia de su carácter de eslabones requeridos por el proceso de progreso. La brutalidad, la crueldad, el dolor, empero, no resultan comprensibles adecuadamente como meros momentos funcionales al despliegue del proceso total. Su significado específico como lo absolutamente rechazable resulta soslayado o reducido, si se los concibe histórico-filosóficamente. De modo semejante, cuando el Estado es entendido hegelianamente, se debilita o se pierde el criterio para enjuiciar las malas acciones de los Estados concretos.

\section{La excepción y el derecho natural}

Al caracterizar el pensamiento schmittiano, se ha visto que en él la excepción juega un papel fundamental. En Teología política escribe Schmitt: "Lo normal no prueba nada, la excepción lo prueba todo; ella no sólo confirma la regla, la regla vive en absoluto sólo desde la excepción. En la excepción irrumpe la fuerza de la vida real en la cáscara de una mecánica paralizada en repetición". ${ }^{67}$ Luego añade un pasaje tomado de Kierkegaard:

La excepción explica lo general y a sí misma. Y si uno quiere estudiar correctamente lo general, uno necesita sólo mirar una auténtica excepción. Ella revela todo con más claridad que lo general. La interminable conversación sobre lo general se vuelve aburrida; hay excepciones. Si ellas no pueden ser explicadas, entonces lo general no puede ser explicado. La dificultad usualmente pasa desapercibida, porque lo

64 Kelsen, 1960, p. 60-61 (nota al pié) 68-70; Kelsen, pp. 21, 255.

65 Cf. Schmitt, 1952, p. 9.

66 Cf. Schmitt, 1950, p. 928; 1952, p. 7.

67 Schmitt, 2009, p. 21. 
general no es pensado con pasión, sino que con una confortable superficialidad. La excepción, en cambio, piensa lo general con intensa pasión. ${ }^{68}$

Estas afirmaciones tienen alcances para el campo jurídico y político, donde Schmitt remarca, de un lado, la dependencia de la regla respecto de una situación real estructurada típicamente ${ }^{69}$ de otro, la relevancia del poder soberano y del estado de excepción para la superación de la excepción, cuanto para la existencia humana como tal. ${ }^{70}$ La excepción schmittiana no es, empero, sólo ni preponderantemente la excepción política. Excepción es también lo indeterminado, ${ }^{71}$ la muerte, ${ }^{72}$ lo infinito, ${ }^{73}$ la trascendencia, ${ }^{74}$ aquello frente a lo cual experimentamos inseguridad y angustia. ${ }^{75}$ Es la radical apertura a lo otro radical. La excepción política es un caso de esa excepción más amplia, por la que está marcada nuestra existencia. Eventualmente, la excepción política puede ser controlada, mediante dispositivos como el estado de excepción y otros artilugios técnicos. Pero Schmitt no cree ni en la eficacia completa de esos mecanismos para superar la excepción política, ni tampoco que baste superar la excepción política para cancelar la posibilidad de excepción en general. Para Schmitt la normalidad se constituye bajo condición de la excepción, la inmanencia bajo condición de la trascendencia. Y nuestro emerger en el mundo, lo mismo que nuestra muerte nos llama la atención respecto a que la excepción es precisamente nuestro modo mismo de existir.

Esta excepción sobre la que se halla emplazada la existencia plantea luego el problema de la compatibilidad entre ley, en este caso, ley natural, y excepción. ¿Cómo volver compatibles los textos en los que Schmitt se refiere a principios prácticos invariables con la idea de la excepción como lo radicalmente abierto y la de una trascendencia insubyugable desde la inmanencia?

Se podría responder que nuestra existencia, no obstante su radical apertura, está determinada por ciertas condiciones de su posibilidad, que, precisamente, posibilitan esa indesmentible apertura. Si estas condiciones no se cumplieran, entonces dejaríamos de existir al modo en que existimos y nos comprendemos. Estas condiciones son tres, y ellas, a la vez que posibilitan nuestra existencia,

68 Schmitt, 2009, p. 21; cf. Kierkegaard, 1983, p. 227.

69 Cf. Schmitt, 2009, p. 19.

70 Cf. Schmitt, 2009, p. 13-21.

71 Cf. Schmitt, 1991a, pp. 36, 264.

72 Cf. Schmitt, 1991a, pp. 39, 93-94.

73 Cf. Schmitt, 1991a, pp. 94-95.

74 Cf. Schmitt, 1991a, pp. 37, 60; Rissing y Rissing, 2009, p. 56.

75 Cf. Schmitt, 1991a, pp. 39, 93, 94. 
son también condición de la apertura. La primera es la diferencia entre trascendencia e inmanencia. Ella es condición de nuestra existencia, en tanto que es desde la distancia radical generada por la trascendencia entre el sujeto y lo conocido, que puede producirse el conocimiento. La completa inmanencia significa para Schmitt la "eliminación de toda distancia", incluso de la "inteligencia", la cual siempre es algo distinto de la pura inmediatez. ${ }^{76}$ En el caso de ausencia total de distancia, nos hallaríamos como fundidos con los fenómenos mismos, en algo así como un éxtasis, en el cual el sujeto se diluiría en los fenómenos y sus experiencias serían incluso "menos que un sueño". ${ }^{77} \mathrm{Si}$ la trascendencia desapareciera de nuestro horizonte de comprensibilidad, no es sólo que dejaríamos de tenerla a ella, es simplemente que ya no comprenderíamos y nos sumiríamos en los rigores de algo así como una fusión con lo conocido.

Esta indicación sobre nuestra inmanencia actual nos lleva a la segunda condición de nuestra existencia, que es también condición de la apertura a la excepción que es esa existencia: nuestra finitud o precariedad. Nuestro modo de existir es el de un ser finito, sin consciencia acerca del acto de emerger en su existencia, ni tampoco del modo de surgimiento de los fenómenos, que simplemente se aparecen ante él, que le son dados. No sabemos de algo así como el fundamento de nuestra existencia, estamos suspendidos sobre un abismo de indeterminación, misterio y posibilidad, suspendidos sobre la trascendencia. ${ }^{78}$ Es este nuestro radical modo de ser actual: ser en la inmanencia a partir de una misteriosa e inabordable trascendencia. ${ }^{79}$ Nuestra finitud significa la precariedad de nuestro existir: existimos, pero podemos dejar de existir, tal como del no-ser emergimos hacia la existencia.

Por último, una tercera condición de nuestra existencia, que es también condición de la apertura a la excepción, es nuestro ser práctico o a la búsqueda de sentido. No sólo existimos en la diferencia inmanencia-trascendencia como seres finitos, sino que además estamos constitutivamente dispuestos a la búsqueda de sentido. Esa búsqueda de sentido es condición de nuestra existencia como seres humanos, pues está en la base de todas nuestras acciones. Incluso en el más especulativo de los actos de conocimiento humano, en la más teórica de las formulaciones teóricas, existe una intención cognoscitiva que guía y desencadena el acto de conocimiento. Sin esa intención, no sería

76 Schmitt, 1991a, p. 84.

77 Kant, "Kritik der reinen Vernunft", A 112 (1998).

78 Cf. Heidegger, 1996, p. 115; Schmitt, 1991a, pp. 60, 212.

79 Cf. Schmitt, 2009, p. 21; Schmitt, 1991a, pp. 93-95. 
posible el dirigirse del ser humano cognoscente hacia el fenómeno por conocer. Puesta esta falta de intención en términos radicales, significaría la pérdida de consciencia o lucidez, que es un aspecto constitutivo de nuestra existencia. ${ }^{80}$ Esta practicidad que ya vale para el conocimiento, vale también para las acciones morales, económicas, políticas, etc. Ellas sólo se dejan elucidar adecuadamente bajo condición de una tensión o un sentido práctico originario. ${ }^{81}$

Estas tres condiciones de nuestra existencia son condiciones de nuestra apertura a la excepción. Si alguna de ellas faltase, no podríamos estar ya más abiertos a ella y a la posibilidad de la irrupción de la trascendencia en la inmanencia. Sin consciencia de la trascendencia, esta pérdida es obvia. Pero además, la apertura a la trascendencia en el modo en que existimos es una comprensión de la excepción desde nuestra finitud. Comprender como lo haría un ser infinito está fuera de nuestras posibilidades de concepción, a tal punto que si llegásemos a ese nivel podríamos sostener que hemos dejado de ser humanos. Sin ser a la búsqueda, simplemente dejaríamos de comprender, de tal suerte que no habría consciencia de la excepción.

En esta explicación, que es compatible con los textos de Schmitt e incluso se deja documentar en ellos (allí reconoce la trascendencia como condición de la inmanencia, la finitud de la existencia y su carácter originariamente práctico), queda espacio para, afirmando la apertura del ser humano a la indeterminación y misterio que es la excepción, sostener todavía una filosofía práctica y algo parecido a lo que la tradición ha llamado derecho natural. Es decir, para dar orientaciones fundamentales acerca de cómo realizar sentido y evitar los daños graves al precario ser humano, incluidos dispositivos jurídicos y políticos de protección y defensa contra agresiones graves, que es algo que Schmitt postula. Vale decir: cabría afirmar no sólo que el tema del derecho natural de hecho se encuentra presente en los textos de Schmitt, como he tratado de mostrar en el punto anterior, sino también que el derecho natural es jurídica o válidamente admisible dentro del marco determinado por una filosofía en la que cabe la excepción, como lo es la de Carl Schmitt. La condición de posibilidad para esta segunda compatibilidad es que dichas indicaciones prácticas se mantengan abiertas a la posibilidad de lo excepcional, de lo inusitado, de lo radicalmente otro, de aquello que, de ocurrir, llegue a alterar incluso el horizonte de su aparecibilidad. En este sentido opera, precisamente, por ejemplo, la temprana crítica schmittiana de la racionalidad técnica como una forma de racionalidad 
cosificante, que se cierra radicalmente a la excepción, a lo trascendente, a lo otro, que termina siendo allí simplemente manipulado. ${ }^{82}$

\section{Referencias bibliográficas}

ARISTÓTELES. "Política”. Madrid: Centro de Estudios Constitucionales, 1989a. . "Ética a Nicómaco". Madrid: Centro de Estudios Constitucionales, 1989b.

BIEN, G. "Einletung”. In: Aristóteles. Politik. Hamburgo: Meiner 1981. pp. XVIILIII.

BÖCKENFÖRDE, E.-W. "Konkretes Ordnungsdenken". In: J. Ritter, Karlfried Gründer (ed.). Historisches Wörterbuch der Philosophie. Basilea: Schwabe Verlag, 1984. Vol. 6, cols. 1312-1315.

D’ORS, A. "El Glossarium de Carl Schmitt”. VV.AA. Estudios sobre Carl Schmitt. Madrid: Fundación Cánovas de Castillo, 1996. pp. 17-48.

GERHARDT, V. "Politik als Ausnahme". In: R. Mehring (ed.). Carl Schmitt. Der Begriff des Politischen. Ein kooperativer Kommentar. Berlín: Akademie Verlag, 2003. HEGEL, G. W. F. "Grundlinien der Philosophie des Rechts". Hamburgo: Meiner, 1999.

HEIDEGGER, M. "Was ist Metaphysik?" Gesamtausgabe 9. Frankfurt a.M.: Klostermann, 1996. pp. 103-122.

HELLER, H. "Staatslehre". Leiden: Sijthoff, 1934.

HERRERA, H. E. "Carl Schmitt als politischer Philosoph. Versuch einer Bestimmung seiner Stellung bezüglich der Tradition der praktischen Philosophie”. Berlín: Duncker \& Humblot, 2010a.

. "Más allá del cientificismo". Santiago de Chile: Ediciones UDP, 2010b.

HERRERO, M. "El nomos y lo político. La filosofía política de Carl Schmitt". Pamplona: EUNSA, 1997.

HOFMANN, H. "Legitimität gegen Legalität". Berlín: Duncker \& Humblot, 2002.

HUBER, E. R. "Positionen und Begriffe - Eine Auseinandersetzung mit Carl Schmitt". Zeitschrift für die gesamte Staatswissenschaft, Vol. 101, 1941, pp. 1-44.

HUME, D. "Treatise of Human Nature". Oxford: Clarendon Press, 1960.

KAISER, J. H. “Konkretes Ordnungsdenken”. In: H. Quaritsch (ed.). Complexio Oppositorum. Berlín: Duncker \& Humblot, 1988. pp. 319-331.

KANT, I. "Kritik der reinen Vernunft". Hamburgo: Meiner, 1998.

KELSEN, H. "Allgemeine Staatslehre". Berlín, Heidelberg, Nueva York: Springer, 1925 . 
KELSEN, H. "Reine Rechtslehre". Viena: Franz Deuticke Verlag, 1960. . “QQué es Justicia?” Barcelona: Ariel, 1982.

KIERKEGAARD, S. "Repetition”. Princeton: Princeton University Press, 1983. KUHN, H. "Der Staat. Eine philosophische Darstellung”. Múnich: Kösel-Verlag, 1967.

LAUFER, H. "Das Kriterium politischen Handelns. Versuch einer Analyse und konstruktiven Kritik der Freund-Feind-Unterscheidung auf der Grundlage der Aristotelischen Theorie der Politik; zugleich ein Beitrag zur Methodologie der politischen Wissenschaften”. Würzburg, 1961 (tesis doctoral).

LÖWITH, K. "Der okkasionelle Dezisionismus von Carl Schmitt". In: Sämtliche Schriften. Stuttgart: Metzler, 1984, Vol. 8, pp. 32-71.

MEIER, H. 'Carl Schmitt, Leo Strauss und 'Der Begriff des Politischen'. Zu einem Dialog unter Abwesenden". Stuttgart: Metzler, 1998.

NIEMEYER, G. "Vorwort”. In: H. Heller. Staatslehre. Leiden: Sijthoff, 1934.

OTTMANN, H. “Ordnung”. In: Staatslexikon. Friburgo/Basilea/Viena 1995, Vol. 4, cols. 189-192.

RISSING, T., RISSING, M. "Politische Theologie. Schmitt-Derrida-Metz". Múnich: Wilhelm Fink, 2009.

SCHMITT, C. "Römischer Katholizismus und politische Form". Stuttgart: KlettCotta, 1984.

Humblot, 1991a.

“Glossarium. Aufzeichnungen der Jahre 1947-1951”. Berlín: Duncker \& . "Theodor Däublers 'Nordlicht'. Drei Studien über die Elemente, den

Geist und die Aktualität des Werkes". Berlín: Duncker \& Humblot, $1991 b$.

. "Über die drei Arten des rechtswissenschaftlichen Denkens". Berlín:

Duncker \& Humblot, 1993a. . "Verfassungslehre". Berlín: Duncker \& Humblot, 1993 b.

. "Der Nomos der Erde im Völkerrecht des Jus Publicum Europaeum".

Berlín: Duncker \& Humblot, 1997a.

. "Der Begriff des Politischen”. Berlín: Duncker \& Humblot, 1997 b.

. "Ex Captivitate Salus. Erfahrungen der Zeit 1945/47”. Berlín: Duncker

\& Humblot, 2002.

"Die Lage der europäischen Rechtswissenschaft". In: Verfassungsrechtliche Aufsätze aus den Jahren 1924-1954. Materialien zu einer Verfassungslehre. Berlín: Duncker \& Humblot, 2003. pp. 386-429.

. "Der Wert des Staates und die Bedeutung des Einzelnen". Berlín: Duncker \& Humblot, 2004.

- "Politische Theologie II. Die Legende von der Erledigung jeder

Politischen Theologie". Berlín: Duncker \& Humblot, 2008.

. "Politische Theologie. Vier Kapiteln zur Lehre von der Souveränität".

Berlín: Duncker \& Humblot, 2009.

. "Die Einheit der Welt". Merkur, Vol. 47, pp. 1-11, 1952. 
SCHMITT, C. "Drei Stufen historischer Sinngebung". Universitas, Vol. 5, pp. 927931, 1950.

STRAUSS, L. "Anmerkungen zu Carl Schmitt, Der Begriff des Politischen". In: H. Meier. Carl Schmitt, Leo Strauss und "Der Begriff des Politischen”. Zu einem Dialog unter Abwesenden. Stuttgart: Metzler, 1998. pp. 99-125.

THIELICKE, H. "Theologische Ethik". Tübingen: Mohr Siebeck, 1987. Vol. 2, 2a parte.

WELZEL, H. "Naturrecht und materiale Gerechtigkeit". Göttingen: Vandenhoeck \& Ruprecht, 1951. 